\title{
Urban forests sustain diverse carrion beetle assemblages in the New York City metropolitan area
}

\author{
Nicole A Fusco ${ }^{1}$, Anthony Zhao $^{2}{ }^{\text {, Jason Munshi-South }}{ }^{\text {Corresp. } 3}$ \\ 1 Louis Calder Center--Biological Field Station, Fordham University, Armonk, NY, USA \\ 2 Department of Entomology, University of Maryland at College Park, College Park, Maryland, United States \\ 3 Louis Calder Center-Biological Field Station, Fordham University, Armonk, NY, USA \\ Corresponding Author: Jason Munshi-South \\ Email address: jason@nycevolution.org
}

Urbanization is an increasingly pervasive form of land transformation that reduces biodiversity of many taxonomic groups. Beetles exhibit a broad range of responses to urbanization, likely due to the high functional diversity in this order. Carrion beetles (Order: Coleoptera, Family: Silphidae) provide an important ecosystem service by promoting decomposition of small-bodied carcasses, and have previously been found to decline due to forest fragmentation caused by urbanization. However, New York City (NYC) and many other cities have fairly large continuous forest patches that support dense populations of small mammals, and thus may harbor relatively robust carrion beetle communities in city parks. In this study, we investigated carrion beetle community composition, abundance and diversity in forest patches along an urban-to-rural gradient spanning the urban core (Central Park, NYC) to outlying rural areas. We conducted an additional study focusing on comparing the current carrion beetle community at a single suburban site in Westchester County, NY that was intensively surveyed in the early 1970's. We collected a total of 2,170 carrion beetles from eight species at 13 sites along this gradient. We report little to no effect of urbanization on carrion beetle diversity, although two species were not detected in any urban parks. Nicrophorus tomentosus was the most abundant species at all sites and seemed to dominate the urban communities, potentially due to its generalist habits and shallower burying depth compared to the other beetles surveyed. Variation between species in body size, habitat specialization, and \% forest area also did not influence carrion beetle communities. Lastly, we found few significant differences in relative abundance of 10 different carrion beetle species between 1974 and 2015 at a single site in Westchester County, NY, although two of the rare species in the early 1970's were not detected in 2015. These results indicate that NYC's forested parks have the potential to sustain carrion beetle communities and the ecosystem services they provide. 


\title{
Urban forests sustain diverse carrion beetle assemblages in the New York City metropolitan area
}

\author{
Nicole A. Fusco ${ }^{1}$, Anthony Zhao ${ }^{2}$ and Jason Munshi-South ${ }^{1, *}$ \\ ${ }^{1}$ Louis Calder Center - Biological Field Station, Fordham University, Armonk, NY, USA. \\ ${ }^{2}$ Department of Entomology, University of Maryland, College Park, MD, USA. \\ *Corresponding author: \\ Jason Munshi-South \\ jmunshisouth@fordham.edu
}

Phone: (914) 273-3078 x20 


\section{Abstract}

2 Urbanization is an increasingly pervasive form of land transformation that reduces biodiversity of

3 many taxonomic groups. Beetles exhibit a broad range of responses to urbanization, likely due to

4 the high functional diversity in this order. Carrion beetles (Order: Coleoptera, Family: Silphidae)

5 provide an important ecosystem service by promoting decomposition of small-bodied carcasses,

6 and have previously been found to decline due to forest fragmentation caused by urbanization.

7 However, New York City (NYC) and many other cities have fairly large continuous forest

8 patches that support dense populations of small mammals, and thus may harbor relatively robust

9 carrion beetle communities in city parks. In this study, we investigated carrion beetle community

10 composition, abundance and diversity in forest patches along an urban-to-rural gradient spanning

11 the urban core (Central Park, NYC) to outlying rural areas. We conducted an additional study

12 focusing on comparing the current carrion beetle community at a single suburban site in

13 Westchester County, NY that was intensively surveyed in the early 1970's. We collected a total of

142,170 carrion beetles from eight species at 13 sites along this gradient. We report little to no effect

15 of urbanization on carrion beetle diversity, although two species were not detected in any urban

16 parks. Nicrophorus tomentosus was the most abundant species at all sites and seemed to dominate

17 the urban communities, potentially due to its generalist habits and shallower burying depth

18 compared to the other beetles surveyed. Variation between species in body size, habitat

19 specialization, and \% forest area also did not influence carrion beetle communities. Lastly, we

20 found few significant differences in relative abundance of 10 different carrion beetle species

21 between 1974 and 2015 at a single site in Westchester County, NY, although two of the rare

22 species in the early 1970's were not detected in 2015. These results indicate that NYC's forested

23 parks have the potential to sustain carrion beetle communities and the ecosystem services they

24 provide. 
25 Introduction

26 The ecological influence of urbanization is increasingly pervasive around the world. In

$272014,54 \%$ of the world's human population resided in urban areas (United Nations 2014) and

28 urban populations increased by $12 \%$ between 2000 and 2010 in the United States (U.S. Census

29 Bureau 2010). Urban landscapes are highly modified for human use, with natural habitats

30 typically occurring only in small, fragmented patches (Saunders, et al. 1991). Fragmentation in

31 cities often decreases species richness, changes community composition, and alters ecosystem

32 processes (Didham 2010). Many species are impacted negatively by urbanization (carnivores-

33 Ordeñana, et al. 2010; arthropods- Sattler, et al. 2010; amphibians- Hamer and Parris 2011; birds

$34 \&$ plants- Aronson, et al. 2013), but effects vary based on the taxonomic group in question

35 (McKinney 2008). For example, studies of arthropod diversity along urban-to-rural gradients

36 have documented a wide variety of responses to urbanization (Hornung, et al. 2007; Niemelä and

37 Kotze 2009; Varet, et al. 2011; Magura, et al. 2013; Savage, et al. 2015; Diamond, et al., 2015).

38 Given the extreme variety of life history traits and habitat use among arthropods, responses to

39 urbanization may be difficult to predict.

40 Carrion beetles use small mammal carcasses as food sources for their young (Scott 1998).

41 These beetles bury carcasses to avoid competition with other scavengers, thus facilitating

42 decomposition and providing considerable ecosystem services. Availability of carrion likely

43 influences the abundance and diversity of carrion beetles. Carrion beetle species compete with

44 each other as well as with other scavenging vertebrates (Scott 1998; Trumbo and Bloch 2002;

45 DeVault, et al. 2010), and invertebrates for this resource (Ratcliffe 1996; Gibbs and Stanton

46 2001). Urbanization alters natural habitats in myriad ways (Grimm, et al. 2008) that may cause

47 local extirpations or reduced abundance of native small mammals (e.g. likely carrion) and carrion 48 beetles in cities. 
50 beetle species richness and abundance in Syracuse, New York. Beetles that persisted in these

51 fragments were primarily small-bodied habitat generalists, and other carrion beetles may have

52 declined in abundance due to lower carcass availability, increased prevalence of other scavengers,

53 or reduced soil and litter quality. Wolf and Gibbs (2004) also found that forest fragmentation

54 decreased carrion beetle diversity and abundance in Baltimore, Maryland. They argued that forest

55 contiguity was an important factor affecting richness, abundance, and diversity of carrion beetles

56 in this city. However, these studies did not directly address whether large parks within core urban

57 areas harbor a substantial diversity of carrion beetles.

58 In this study we investigated species richness, diversity, relative abundance and

59 community similarity of carrion beetles (Family: Silphidae) across an urban-to-rural gradient in

60 the New York City (NYC) metropolitan area. NYC is the most densely populated area in North

61 America, but $20 \%$ of the city's land area is comprised of vegetated natural areas, particularly

62 within several large urban parks. These parks are characterized by substantial forest cover and

63 high densities of small mammals (Munshi-South and Kharchenko 2010), and thus may provide

64 high-quality habitat for a diverse assemblage of carrion beetles. Alternatively, NYC's urban

65 forests may harbor less carrion beetle diversity relative to suburban and rural areas outside of

66 NYC as was found in Baltimore and Syracuse (Gibbs and Stanton 2001; Wolf \& Gibbs 2004).

67 We also compared historical records from a single site (Pirone and Sullivan, 1980), the Louis

68 Calder Center in Armonk, New York, with our 2015 estimates of carrion beetle diversity and

69 abundance to examine changes over the last four decades. The forest area at the Louis Calder

70 Center has not changed in that time, but urbanization of the surrounding area and a rapid increase

71 in deer herbivory may have resulted in altered diversity of community composition of carrion

72 beetles. 
74 (Faeth, et al. 2011; Elmqvist, et al. 2013; La Sorte, et al. 2014; Aronson, et al. 2014). Diamond, et

75 al. (2015) argued that increases in biodiversity may be due to introduction of non-native species

76 as well as increased habitat heterogeneity in densely populated areas, but many native species

77 still persist in these urban remnants. Urban carrion beetle diversity that rivals surrounding rural

78 areas would indicate that urban forests in NYC currently provide ample habitat and resources to

79 sustain these native beetle communities.

\section{Materials \& Methods}

\section{Study site and sampling techniques}

82 This study was conducted across an urban-to-rural gradient spanning $120 \mathrm{~km}$ from the

83 urban core of NYC (Central Park, Manhattan) to southern New York State and western

84 Connecticut. Carrion beetles were collected from five urban sites in New York City, five

85 suburban sites and three rural sites (Table 1, Figure 1). Urban, suburban and rural site

86 classifications followed Munshi-South et al. (2016) and were based on percent impervious

87 surface cover. Many of our sampling sites were previously used by Munshi-South et al. (2016) to

88 examine population genomics of white-footed mice (Peromyscus leucopus) and thus

89 classifications were already available. For sites unique to this study, we used the same methods to

90 quantify urbanization (Table 1, Figure 1). In brief, we created $2 \mathrm{~km}$ boundary buffers around our

91 study sites in ArcGIS 10.3 (ESRI, 2014) and then used zonal statistics to calculate mean percent

92 impervious surface from the Percent Developed Imperviousness data layer imported from the

93 National Land Cover Database 2011 (Xian, et al. 2011).

94 For comparison with previous carrion beetle surveys in other cities, we followed the

95 sampling methods and trap design employed by Gibbs and Stanton (2001) and Wolf and Gibbs

96 (2004). We constructed traps from open-topped cylinders by cutting the top off 1 L plastic bottles, 
97 adding a loop of string to hang the trap, and attaching a rain cover (cardboard covered in plastic

98 cling wrap) by threading it through the string. Most traps contained $200 \mathrm{~mL}$ of a 1:1 mixture of

99 ethylene glycol and water, although soapy water was substituted at the Manhattan sites due to

100 public safety regulations. A small glass jar containing bait ( $6.5 \mathrm{~cm}^{2}$ of rotting chicken thigh) was

101 topped with a punctured lid to prevent insects from destroying the bait but permitting odors to

102 attract carrion beetles. This jar was placed inside each plastic trap that was then filled with the

103 ethylene glycol mixture. We set three traps at each site, close to forest edges and at least $100 \mathrm{~m}$

104 apart. Traps were hung from small tree branches approximately $1-1.5 \mathrm{~m}$ from the ground to

105 prevent other wildlife from disturbing the traps. Traps were set out for seven consecutive days at

106 each site, where beetles were collected upon the last day. We conducted all trapping from 22 June

107 to 05 August 2015. At each study location, we separated beetles from other insects, and stored

108 beetles in $80 \%$ ethanol before bringing all specimens to the laboratory for identification. We

109 identified all carrion beetle species following Hanley and Cuthrell (2008). After collection, all

110 beetles were stored in ethanol at $-20^{\circ} \mathrm{C}$. Permission to collect carrion beetles was granted by the

111 New York City Department of Parks and Recreation, the Rockefeller State Park Preserve, and the

112 Connecticut Department of Energy and Environmental Protection (Permit number: 1214008).

\section{Relative abundance at urban, suburban and rural sites}

114 To describe variation among sites and site classes we calculated relative abundance as the

115 proportion of each species compared to the total number of individuals at each site. To examine

116 changes over the summer season in carrion beetle diversity and relative abundance at the Louis

117 Calder Center (a suburban site), we conducted three separate trapping surveys, from 22-29 June,

118 14-21 July, and 22-29 July 2015. Only data collected from the third survey were used in the main

119 urban-to-rural analysis to more accurately compare to samples taken during the same time period 
120 as sampling at the other sites (mid to late July 2016). We calculated the relative proportion of

121 each species for each of the three surveys at the Louis Calder Center to examine changes

122 throughout the study period.

\section{Historical comparison of carrion beetle presence and abundance}

124 Pirone and Sullivan (1980) performed carrion beetle sampling at the Louis Calder Center

125 in Armonk, NY for an 8-month period (April-November) in 1974. They collected 4,300 silphid

126 beetles in 6 pitfall traps. Although the current study is only a snapshot ( 3 weeks of sampling) of

127 the current community assembly at this site, the current data collected in 2015 from all three

128 surveys at the Louis Calder Center (June to July) were used to compare the current carrion beetle

129 species (2015) with the species observed in the historical study (1974). A student's t-test was

130 conducted to compare total relative abundance in 1974 to 2015.

\section{Species diversity and species richness along an urban-to-rural gradient}

132 To determine whether our sample size was robust enough for running subsequent

133 statistical analyses we performed a rarefaction analysis for all sites in R v.3.2.3 (R Core Team

134 2015) using the vegan package. For the analysis along the urban-to-rural gradient we used two

135 different measures; species richness and species diversity. To compare species diversity across

136 sites, we calculated the Simpson's reciprocal index (1/D; Simpson 1949) of diversity. We also

137 calculated other diversity indices for comparison (equations; Jost 2006; Table S1). These results

138 showed similar trends across sites for all indices, therefore we chose to use the very commonly

139 used Simpson's reciprocal index for statistical analyses. We then calculated community similarity

140 using the Jaccard Index of community similarity (Jaccard, 1901):

$$
\mathrm{CC}_{\mathrm{J}}=\mathrm{S}_{\mathrm{J}}=\mathrm{a} /(\mathrm{a}+\mathrm{b}+\mathrm{c})
$$

142 where $\mathrm{S}_{\mathrm{J}}$ is the Jaccard similarity coefficient, a is the number of species shared by all sites, $\mathrm{b}$ is 
143 the number of species unique to the first site, and $\mathrm{c}$ is the number of species unique to the second

144 site. Then we calculated the Jaccard coefficient of community similarity for all the data pooled

145 across sites classes (urban, suburban and rural) to analyze overall carrion beetle community

146 assemblages. Lastly, we conducted a hierarchical cluster analysis using the betapart package in R

147 (Baselga \& Orme, 2012) to explore patterns of beta diversity partitioning this diversity measure

148 into the nestedness and the turnover components.

149 To examine the influence of urbanization on species richness and diversity, we calculated 150 general linear regressions of mean percent impervious cover versus species richness and species

151 diversity at each site using $\mathrm{R}$. We also calculated a general linear regression to explore the

152 difference in relative abundance of the most abundant species; Nicrophorus tomentosus versus

153 mean percent impervious surface at all sites. Additionally, we performed a gradient analysis by

154 creating a Non-metric Multidimensional Scaling (NMDS) plot using the Vegan package

155 (Oksanen, et al. 2016) in R to investigate population dissimilarity based on site class (urban,

156 suburban, and rural). NMDS compares species changes from one community to the next by using

157 rank order comparison and calculates the pairwise dissimilarity of points in low-dimensional

158 space (Buttigieg and Ramette 2014). Thus, NMDS allows us to robustly estimate dissimilarity

159 between site locations based on the type of site and the species located in each site.

160 Species-specific differences compared across urban, suburban, and rural sites.

161 Many studies on beetles have focused on specific characteristics that may underlie

162 differences in species richness and diversity within sites and across studies (Davies, et al. 2000).

163 We conducted a factorial ANOVA to examine the interaction effect of species body size (small $<$

$1645 \mathrm{~mm}$, medium $=5-6.5 \mathrm{~mm}$, large $>6.5 \mathrm{~mm}$; estimations and groupings based on data from Gibbs

165 and Stanton 2001) and site classification (urban suburban, rural) based on relative abundance. We

166 also used a Student's t-test to examine relative abundance when species are classified as habitat 
167 generalists versus habitat specialists (Gibbs and Stanton 2001). Lastly, we performed a general

168 linear regression to explore if a relationship exists between species richness or species diversity

169 and the forest area (\%) existing at each site. At each site the forest area was calculated using the

170 Tabulate area tool from the ArcGIS 10.3 (ESRI 2014) Toolbox to calculate the forest area within

171 the same $2 \mathrm{~km}$ buffers surrounding each site as was used to calculate percent impervious surface.

172 We then calculated the relative proportion of forest area compared to the total area within the

173 buffer. We used forest area data from the USGS National Landcover Dataset (Homer et al. 2011).

\section{Results}

175 Relative abundance at urban, suburban and rural sites

176 We collected a total of 2,170 carrion beetles comprising eight silphid species (Table 2)

177 across all sites (Table 1, Figure 1). Nicrophorus tomentosus was the most abundant at all sites,

178 accounting for $56.8 \%$ of all beetles captured (Figure 2), yet there was no significant relationship

179 between $\mathrm{Ni}$. tomentosus relative abundance and percent mean impervious surface of each site

$180(F(2,10)=1.16, p>0.05)$. Other species also varied in presence or abundance between urban,

181 suburban and rural forests (Figure 2); specifically, Oiceoptoma noveboracense was captured

182 more often in suburban areas $(23.5 \%)$ and urban areas $(21.9 \%)$ than at rural sites $(1.6 \%)$, whereas

183 Nicrophorus defodiens was captured predominantly in rural areas (7.1\%) versus urban areas

$184(0.3 \%)$ and suburban areas (0.2\%). Similarly, Necrophila americana was recorded in suburban

$185(8.4 \%)$ and rural areas $(4.3 \%)$ but was not found in any urban sites. Nicrophorus sayi was only

186 recorded at one rural park, accounting for $1.4 \%$ of the total number of beetles captured at rural

187 sites (Table, 1, 2, and Figure 2). 
190 throughout summer 2015. Five carrion beetle species were observed at Louis Calder Center with

191 the absence of $\mathrm{Ni}$. defodiens, $\mathrm{Ni}$. sayi and Oiceoptoma inaequale found at other suburban and

192 rural sites. Nicrophorus pustulatus and Necrophila americana were absent from the first surveys

193 and appeared in later surveys. $\mathrm{Ni}$. tomentosus became more prevalent $(34.4 \%, 54.5 \%, 74.0 \%)$

194 throughout the summer and $O$. noveboracense decreased in relative abundance $(34.4 \%, 28.3 \%$,

$1953.1 \%$; Figure 3).

196 Results of carrion beetle observations at the Louis Calder Center site show a small

197 reduction in species richness; 7 species in 1974 to 5 species in 2015 (Figure 3). Ni. defodiens, Ni.

198 sayi, and O. inaequale were absent both historically and currently at this site yet were present at

199 other suburban sites. The two species not observed in 2015 that were already low in relative

200 abundance in 1974 were Necrodes surinamensis (0.2\%) and Necrophilus pettiti (0.3\%; Figure 4).

201 There was no significant difference in the relative abundance of species in 1974 to 2015

$202(\mathrm{t}(9)=0.546, p=0.599)$. The 2015 data show an increasing trend in the relative abundance of $N i$.

203 tomentosus (5.8\% to 54.3\%) in 1974 versus 2015, and a decreasing trend in the relative

204 abundance of Necrophila americana (41.8\% to 6.7\%) and O. noveboracense (38\% to $21.9 \%$ )

205 since 1974 (Figure 4).

206 Species diversity and species richness along an urban-to-rural gradient

207 Across the urban-to-rural gradient there was no significant relationship between mean

208 percent impervious surface of a site and carrion beetle species richness $\left(R^{2}=0.028, p>0.05\right)$ or

209 species diversity $\left(R^{2}=0.0213, p>0.05\right)$. However, NMDS ordination plots exhibit dissimilarity

210 in carrion beetle assemblages in rural and urban sites. NMDS also showed that beetle

211 assemblages in suburban sites were more similar to those in the urban sites. Based on the size of 
212 the convex hulls, heterogeneity of carrion beetle species composition was the greatest for

213 suburban sites and least for urban sites (Figure 5).

214 We observed relatively high community similarity indices across most pairwise

215 comparisons $(\mathrm{CCj}=0.333-1.000$; Table 3$)$. Several pairs of nearby sites had very high

216 community similarity, such as two urban sites: Inwood Hill Park and New York Botanical Garden

$217(\mathrm{CC} j=1.000)$; and two suburban sites: Convent of the Sacred Heart School and Louis Calder

218 Center $(\mathrm{CC} j=1.000)$. The most distant pairs of sites were less similar, most notably between

219 highly urbanized Central Park and rural Clarence Fahnestock State Park $(\mathrm{CCj}=0.333)$. The

220 pooled urban carrion beetle community was more similar to the pooled suburban community

$221(\mathrm{CC} j=0.857)$ than to the pooled rural community $(\mathrm{CC} j=0.750)$, as also demonstrated in the

222 NMDS ordination (Figure 5). The pooled rural community was equally similar to both the pooled

223 urban and suburban communities $(\mathrm{CC} j=0.750)$. The nestedness component of beta diversity in

224 the hierarchical cluster analysis clustered sites based on species richness trends, not based on site

225 classifications (Figure 6A). Alternatively, the hierarchical clustering of the turnover component

226 clusters all urban sites together with a few suburban sites in one branch and all rural sites and the

227 other suburban sites in another cluster (Figure 6B) as reflected by the results of the NMDS plot

228 (Figure 5).

229 Species-specific differences compared across urban, suburban, and rural sites.

230 We found no significant effect between beetle body size and site class (urban, suburban,

231 rural) for relative abundance of carrion beetle species in this study. Additionally, when focusing

232 on habitat specialization, we also found no significant difference in habitat specialization between

233 urban, suburban, and rural sites (Table S1). Lastly, we found no trend in species richness (Figure 
234 S1A) or species diversity (Figure S1B) across increasing continuous forest areas throughout 235 sampled sites.

\section{Discussion}

237 Contrary to our predictions, we observed few differences in beetle diversity or richness

238 along an urban-to-rural gradient in the NYC metropolitan area. Along this gradient, urban and

239 suburban sites were nearly equally diverse and species-rich as rural sites. We also detected little

240 to no influence of urbanization (measured by mean percent impervious surface) on relative

241 species abundance, species diversity or species richness of carrion beetles throughout these sites.

242 Although species richness is not very high, we observed relatively high carrion beetle community

243 similarity values between most pairs of sites in this study regardless of their urbanization status

244 (Jaccard Index = 0.333-1.000; Table 3). When partitioning beta diversity, nestedness follows

245 species richness trends, further strengthening the result that there is no difference in carrion beetle 246 communities between urban, suburban and rural classified sites. Alternatively, turnover may be

247 driven by site class based on urbanization to some extent.

248 Overall, even with limited sampling, this study demonstrates that a diverse community of

249 carrion beetles are able to thrive in rural, suburban and urban forests in and around New York

250 City. Gibbs and Stanton (2001) and Wolf and Gibbs (2004) reported that carrion beetle diversity

251 is significantly reduced around Syracuse, NY and Baltimore, MD due to forest fragmentation

252 associated with urbanization, but our results indicate that forested city parks in the most

253 urbanized areas of North America (i.e. Manhattan and the Bronx, NYC) do harbor substantial

254 carrion beetle diversity compared to surrounding rural areas. We did not directly examine

255 variation in fragment size within urban, suburban, and rural areas, but the discrepancy between 
256 these earlier results and ours may be due to the fact that urban forests in NYC parks are relatively

257 large compared to other cities.

258 Arthropods have exhibited highly variable, even dichotomous, responses to urbanization

259 around the world (Lessard and Buddle 2005; Sattler, et al., 2010). Other studies show that the

260 influence of urbanization varies based on taxonomic group, geographic location, climate and

261 spatial scale (McKinney 2008; Kotze, et al. 2011, Martinson and Raupp 2013). Carabid beetles

262 are the most well-studied arthropod group: carabid species richness has been found to decrease

263 (Gaublomme, et al. 2008) or not change (Dieschel 2006) in urban areas. In a review of carabids

264 and urbanization, Magura et al. (2010) argued that this variation was due to site-specific effects

265 operating in each study. Urbanization did not homogenize carabid assemblages in cites in

266 England, Denmark, and Helsinki, Finland, but urbanization did affect species assemblages in

267 other Finnish cities, Hungary, Japan and Bulgaria (Kotze, et al. 2011). Other than location,

268 discrepancies across studies may be related to the choice of variables for analysis. Differing

269 climates, different measures of urbanization (e.g. human population density, economics, housing

270 density, or impervious surface), different times of the year studies were conducted, and spatial

271 scale (Faeth, et al. 2011) all could affect species presence, richness, and diversity results in urban

272 areas. Although carrion beetles are may not be representative of all arthropod species, these same

273 factors may also explain some of the differences between the NYC results presented here, and

274 those of Gibbs and Stanton (2001) and Wolf and Gibbs (2004) for Syracuse, NY and Baltimore,

275 MD.

276 When quantifying and classifying urbanization, many studies use measures based on

277 forest fragmentation, extent of forest cover, isolation caused by human-induced disturbance,

278 impervious surface, or human population density (Macdonnell and Hahs 2008). The use of a

279 common index to represent urbanization is necessary to compare results across studies, but there

280 are no common indices currently in wide use. Macdonnell and Hahs (2008) and Kotze, et al. 
281 (2011) stress the need for such common measures to examine the generality the influence of

282 urbanization on biodiversity patterns. Comparing our study to other carrion beetle studies, we

283 used mean percent impervious surface to quantify urbanization, whereas Gibbs and Stanton

284 (2001), Wolf and Gibbs (2004) and Klein (1989) utilized continuous forest cover and

285 fragmentation to classify the level of urbanization at each site. Our study specifically quantified

286 urbanization with mean percent impervious surface using $2 \mathrm{~km}$ buffers as was previously

287 reported by Munshi-South, et al. (2016) for many of the same study sites. Although many metrics

288 can be employed to measure urbanization, we believe that impervious surface cover is

289 particularly useful for urban-to-rural gradient studies because it is measurable for nearly any

290 terrestrial area and directly related to urban landscape modification.

291 We also examined species relative abundance changes over three sampling periods at a

292 suburban site: the Louis Calder Center in Westchester County, NY. Despite no significant change

293 in total abundance across samples throughout the summer season, we did see slight changes in

294 species abundance over different collection periods (Figure 3). In comparison to Wolf and Gibbs

295 (2004) our study showed opposite trends in species presence across the collection period. This

296 difference could be due to difference in climate and temperature across June, July, and August in

297 NYC versus the more southern Baltimore, MD. In Armonk, NY, Ni. tomentosus, $O$.

298 noveboracense, and O. inaequale were more abundant later in the summer, and Ni. orbicollis was

299 more abundant earlier in the summer. Scott (1998) describes Ni.tomentosus as a late summer /

300 early fall breeder, which was corroborated by our observation that Ni. tomentosus was most

301 abundant in the latest summer survey. Ni. orbicollis begins breeding in late spring (Ratcliffe

302 1996), and was the most abundant in our first sample session at this site. Ni. sayi is most active in

303 very early spring, which may explain the absence of this species at this site during the summer.

304 Lastly, the absence of Ni. pustulatus may be due to their habitat preference for wetlands (Gibbs

305 and Stanton 2001), which were not very extensive around our trap sites in this study. 
306 Species richness of carrion beetles did not differ greatly between 1974 and 2015 at the

307 Louis Calder Center site. However, we did record pronounced species-specific differences in 308 abundance between the past study (Pirone and Sullivan, 1980) and this current study in 2015

309 (Figure 4). Species differences over time could be due to anthropogenic modification of the

310 landscape in and around the Louis Calder Center site since the early 1970s. There was an increase

311 in human population density in the town of North Castle, NY in Westchester County from 9,591

312 (1970) to 11,841 (2010) according to the Decennial Census 1950-2010 (U.S Census Bureau,

313 2010). An increase in population density often results in construction of more housing and roads

314 and subsequent fragmentation of forests, which could alter current species assemblages. We

315 identified the most drastic change in relative abundance over time for 3 species; Ni. tomentosus,

316 O. noveboracense and Necrophila americana (Figure 4). In contrast, relative abundance of $\mathrm{Ni}$.

317 tomentosus increased, which could be due to the fact that this species is an ecological generalist

318 that becomes more common after habitat degradation. There was a substantial decrease in $O$.

319 noveboracense since 1974. Since univoltine arthropod species are more affected by habitat loss,

320 (Kotze et al. 2011) the reduction in O. noveboracense may be due to their inability to effectively

321 compete with multivoltine species, as well as their limited dispersal ability in warmer

322 temperatures (Ratcliffe 1996). Lastly, the most drastic decline was in Necrophila americana,

323 which is perhaps due to its large body size (smaller bodied generalists can survive in more

324 disturbed/urban habitat; Gibbs and Stanton 2001; Elek and Lovei, 2007) and its preference for

325 field habitat (Ratcliffe 1996), which may be more limited in the area in 2015 due to

326 fragmentation and the reduction in agriculture. Two previously-observed species, Necrodes

327 surinamensis and Necrophilus pettiti, were completely absent in our contemporary sample.

328 Necrodes surinamensis is nocturnal and highly attracted to artificial lights, causing Ratcliffe

329 (1998) to state concern for this species in cities where increased nocturnal lighting is common.

330 This may be the reason for the decrease or even the extirpation of this species at this site. As for 
331 Necrophilus pettiti, it is a flightless carrion beetle species (Peck 1991), possibly limiting its

332 dispersal and survivability in increasingly urbanized areas. Alternatively, our use of hanging traps

333 rather than pitfall traps as in Pirone and Sullivan (1980) may explain the absence of this flightless

334 species in our study.

335 In their study, Gibbs and Stanton (2001) discuss several ecological factors that may

336 influence the presence and relative abundance of carrion beetles in urban areas. The first limiting

337 factor is the availability of carcasses. However, urbanization can lead to an increase in abundance 338 of some birds and small mammals (Faeth, et al. 2011; Pickett, et al. 2011). Forests in New York

339 City typically contain large rodent populations (particularly white-footed mice and chipmunks),

340 as well as abundant songbird populations (Ekernas and Mertes 2006; Seewagen and Slayton

341 2008). Availability of bird and small mammal carcasses in urban parks may be higher than

342 previously appreciated, and may explain the abundance of some generalist species ( $\mathrm{Ni}$.

343 tomentosus) in NYC.

344 Competition with scavengers may also limit carrion beetle abundance and diversity.

345 Competitors for carrion include other invertebrates (flies and mites- Gibbs and Stanton 2001) and

346 many vertebrate mesopredators that are abundant in cities (raccoons, opossums, coyotes, skunks-

347 DeVault, et al. 2011). However, Suguira, et al. (2013) recently reported that resource competition

348 between invertebrates and vertebrates for carrion was less prevalent than previously thought.

349 Vertebrate competitors are likely present at all of our study sites but may not substantially

350 influence carrion beetle abundance, particularly if they are utilizing food resources provided by

351 humans in cities. As for intraspecific competition with other carrion beetle species, Scott (1998)

352 found there to be competition between Ni. orbicollis and Ni. defodiens based on temperature.

353 Trumbo \& Bloch (2002) found that Ni. defodiens can locate carcasses sooner than other species,

354 but $\mathrm{Ni}$. orbicollis uses cues from $\mathrm{Ni}$. defodiens to locate and subsequently dominate carrion. We

355 identified a higher abundance of $\mathrm{Ni}$. orbicollis than $\mathrm{Ni}$. defodiens, especially in urban and 
356 suburban sites (Figure 2). Greater abundance of Ni. orbicollis in our sites could be due to these

357 competitive abilities that aid Ni. orbicollis in locating and dominating prey more effectively.

358 Lastly, intraspecific invertebrate competitors such as flies are often very prevalent in human

359 altered landscapes (Kavazos and Wallman 2012). Flies are known to quickly locate carcasses and

360 may outcompete beetles on carrion (Scott, 1987; Scott \& Traniello 1990; Trumbo 1990; Gibbs

361 and Stanton 2001). If there is fly abundance in NYC parks, our study indicates that this

362 intraspecific competition is not restricting beetle abundance in urban forests compared to

363 suburban and rural forests. Some carrion beetles have also evolved adaptations to thwart fly

364 competition. For example, Ni. tomentosus was the most abundant carrion beetle in urban forests

365 in this study, and may be thriving partially due to its cooperative burying behavior rapidly

366 conceals carcasses from flies during times of day when flies are most active (Scott, et al. 1987).

367 Gibbs and Stanton (2001) also identify soil compaction as a negative influence on carrion

368 beetles in urban areas. Soil compaction is characteristic of urban forests due to trampling by

369 humans and other factors, and may impede the ability of beetles to dig and bury carcasses in

370 urban soils (Gibbs and Stanton 2001; Pouyat et al. 1994). The relatively shallow burying of $\mathrm{Ni}$.

371 tomentosus may be another factor promoting the success of this species in NYC (Figure 2). In the

372 study by Wolf and Gibbs (2004) they found soil compaction to not be correlated with urbanized

373 land, but was partially correlated with forest extent. Additionally, larger forest area has been

374 shown to support greater diversity of burying beetles (Gibbs and Stanton 2001). NYC's urban

375 parks seem to contain sufficiently extensive tracts of forest for carrion beetles to persist despite

376 possible soil compaction.

377 We found no trend in body size (as classified via Scott 1998 \& Gibbs and Stanton 2001),

378 across habitat specialization (from Gibbs and Stanton, 2001), or with continuous forest habitat

379 area compared to abundance of species found in urban, suburban and rural sites (Supplementary

380 Fig. 3,4,5). Our results of body size and habitat specialization were again contradictory to past 
381 burying beetle literature where Ulrich, et al. (2007) found a negative association between body

382 size of necrophagous beetles and distance from the city center in northern Poland. Gibbs and

383 Stanton (2001) also reported that carrion beetles thriving in urban areas were often small-bodied

384 and habitat generalists. Magura et al. 2006 used even more stringent statistical measures to assess

385 carabid beetle body size across an urbanization gradient. These studies measured body length and

386 / or biomass of each individual, whereas our study was limited by gross approximation of body

387 sizes classes, which may have caused us to miss this effect. In a broader analysis of 69 beetle

388 species (Davies et al. 2000), body size was not correlated with fragmentation. The authors argued

389 that the relationship between extinction risk and body size is very complex and influenced by

390 other factors like spatial scale, population fluctuation, and longevity.

391 In general, our study shows that within NYC, urban parks are able to house nearly the

392 same community as continuous forest tracts in the rural surrounding areas despite local

393 impervious surface and ecological / life history variability across species. These results highlight

394 the importance of maintaining and conserving large areas of forest throughout NYC within city

395 parks commonly used for human recreation.

\section{Conclusions:}

Urban parks have the potential to house diverse habitats rich in biodiversity (Kotze, et al.

398 2011) of both plants and animals (Angold, et al. 2006). Even highly modified landscapes

399 containing small reserves comprising ample green space have the potential to house large beetle

400 diversity (Watts and Lariviere 2004) and high abundance of other arthropod species (Bolger,

401 2008; Faeth, et al. 2011). The maintenance of arthropod biodiversity in urban parks may

402 ultimately be mediated by human influence on plant communities (Faeth, et al. 2011).

403 Alternatively, arthropod species thriving in urban habitats may be preadapted for tolerance to

404 fragmentation and high colonization potential (Sattler, et. al 2010). A current review on 
405 biodiversity in cities suggests that patch area and corridors have the strongest positive effect on

406 biodiversity and that we need to maintain sites with larger than 50 hectares to prevent rapid loss

407 of sensitive species (Beninde, et al. 2015). Maintenance of carrion beetle diversity in NYC will

408 stabilize the interconnectedness of urban food webs, aid in nutrient cycling, and promote natural

409 decomposition of carcasses (Beasley, et al. 2015) in our urban parks. Sustaining the ecosystem

410 services provided by carrion beetles will require conservation of large, continuous forest tracts in

411 urban parks. Greater connectivity between small green areas, and connectivity between the urban

412 core and surrounding forested areas will promote the biodiversity potential of small patches (Doo

413 and Joo, 2011). A "land sparing city" approach is one way to maintain essential ecosystem

414 services (Stott, et al. 2015) provided by carrion beetles in the New York City area.

415 Acknowledgements: We thank Matthew Combs and Jane Park for photographing carrion

416 beetles, and Elizabeth Carlen, Carol Henger, and Emily Puckett for helpful comments on the

417 manuscript. Gabor Lovei and two anonymous reviewers also provided very thorough and

418 constructive suggestions for improving the manuscripts.

\section{References}

420 Angold, PG, Sadler, JP, Hill, MO, Pullin, A, Rushton, S, Austin, K, Small, E, Wood, B, 421 Wadsworth, R, Sanderson, R, Thompson, K. (2006) Biodiversity in urban habitat patches.

422 Science of the Total Environment. 360; 196-204.

423 Aronson, MFJ, Sorte, FA, Nilon, CH, Katti, M, Goddard, MA, Lepczyk, CA, Warren, PS, 424 Williams, NSG, Cilliers, S, Clarkson, B, Dobbs, C, Dolan, R, Hedblom, M, Klotz, S, Kooijmans, 425 JL, Kuhn, I, MacGregor-Fors, I, McDonnell, M, Mortberg, U, Pysek, P, Siebert, S, Sushinsky, J, 426 Werner, P, Winter, M. (2014) A global analysis of the impacts of urbanization on bird and plant 427 diversity reveals key anthropogenic drivers. Proceedings of the Royal Society B Biological 428 Sciences, 281, 20133330.

429 Baselga, A \& Orme, CDL. (2012) Betapart: An R package for the study of beta diversity. 430 Methods in Ecology \& Evolution. 3, 808-812. 
431 Beasley, JC, Olson, ZH, Devault, TL. (2015) "Ecological Role of Vertebrate Scavengers" USDA

432 National Wildlife Research Center, Staff Publications, CRC Press, 107-127.

433 Beninde, J, Veith, M, Hochkirch, A. (2015) Biodiversity in cities needs space: A meta-analysis 434 of factors determining intra-urban biodiversity variation. Ecological Letters, 18; 581-592.

435 Bolger, DT, Beard, KH, Suarez, AV, Case, TJ. (2008) Increased abundance of native and non 436 native spiders with habitat fragmentation. Diversity and Distributions, 14, 655-665.

437 Buttigieg PL, Ramette A. (2014) A Guide to Statistical Analysis in Microbial Ecology: a 438 community-focused, living review of multivariate data analyses. FEMS Microbial Ecology, 90 : $439543-550$.

440 Davies, KF, Margules, C. (2000) Which Traits of Species Predict Population Declines 441 In Experimental Forest Fragments? Ecology, 81; 1450-1461.

442 Deichsel, R. (2006) Species change in an urban setting-ground and rove beetles (Coleoptera: 443 Carabidae and Staphylinidae) in Berlin. Urban Ecosystems. 9; 161-178.

444 Dekeirsschieter J, Verheggen FJ, Haubruge E, Brostaux Y. (2011) Carrion beetles visiting pig 445 carcasses during early spring in urban, forest and agricultural biotypes of Western Europe.

446 Journal of Insect Science, 11:73.

447 DeVault, TL, Olson, ZH, Beasley, JC, Rhodes, OE. (2011) Mesopredators dominate competition 448 for carrion in an agricultural landscape. Basic and Applied Ecology, 12; 268-274.

449 Diamond, SE, Dunn, RR, Frank, SD, Haddad, NM, Martin, RA. (2015) Shared and unique 450 responses of insects to the interaction of urbanization and background climate. Current Opinion 451 in Insect Science, 11, 71-77 (2015).

452 Didham, RK. (2010) Ecological Consequences of Habitat Fragmentation. Encyclopedia of Life 453 Sciences, John Wiley \& Sons Ltd, Chichester. http://www.els.net [doi:

454 10.1002/9780470015902.a0021904]

455 Do, Y, Joo, GJ. (2013) The effect of fragmentation and intensive management on carabid beetles 456 in coniferous forest. Applied Ecology and Environmental Research, 11; 451-461.

457 Ekernas, SL, Mertes, KJ. (2006) The influence of urbanization, patch size, and habitat type on 458 small mammal communities in the New York Metropolitan Region. WildMetro, New York, NY. 459 http://www.wildmetro.org/WMsmallmammal.pdf

460 Elek, Z. \& Lövei, GL. (2007) Patterns in ground beetle (Coleoptera: Carabidae) assemblages 461 along an urbanization gradient in Denmark. Acta Oecologica 32, 104-111.

462 Elmqvist, T, Fragkias, M, Goodness, J, Güneralp, B, Marcotullio, PJ, McDonald, RI, Parnell, S, 463 Schewenius, M, Sendstad, M, Seto, KC, Wilkinson, C. (2013) Urbanization, Biodiversity and 464 Ecosystem Services: Challenges and Opportunities: A global assessment. Springer, 2013. 
465 ESRI (Environmental Systems Resource Institute). (2014) ArcMap 10.3. ESRI, Redlands, 466 California.

467 Eversham, BC, Roy, DB, Telfer, MG. (1996) Urban, industrial and other manmade sites 468 as analogues of natural habitats for Carabidae. Annals of Zoology Fennici, 33; 149-156.

469 Faeth, SH, Bang, C, Saari, S. (2011) Urban biodiversity: Patterns and mechanisms. Annals of the 470 New York Academy of Sciences, 1223; 69-81.

471 Gaublomme, E, Hendrickx, F, Dhuyvetter, H, Desender, K. (2008) The effects of forest patch 472 Size and matrix type on changes in carabid beetle assemblages in an urbanized landscape.

473 Biological Conservation, 141, 2585-2596.

474 Gibbs, JP, Stanton, EJ. (2001) Habitat Fragmentation and arthropod community change: carrion 475 beetles, phoretic mites, and flies. Ecological Applications, 11(1); 79-85.

476 Grimm, NB, Faeth, SH, Golubiewski, NE, Redman, CL, Wu, J, Bai, X, Briggs, JM. (2008) 477 Global Change and the Ecology of Cities. Science. 319; 756-760.

478 Hamer, AJ \& Parris, KM. (2011) Local and landscape determinants of amphibian communities 479 in urban ponds. Ecological Applications, 21, 378-390.

480 Hanley, GA, Cuthrell, DL. (2008) Carrion Beetles of North Dakota: Including species 481 descriptions and identification keys for the entire North American Silphid fauna. Cyril Moore 482 Science Center Science Monograph, 4: 1-52.

483 Homer, CG, Dewitz, JA, Yang, L, Jin, S, Danielson, P, Xian, G, Coulston, J, Herold, ND, 484 Wickham, JD, and Megown, K. (2011) 2011 National Land Cover Database for the conterminous 485 United States-Representing a decade of land cover change information. Photogrammetric 486 Engineering and Remote Sensing, 81(5): 345-354.

487 Hornung, EB, Tothmeresz, T, Magura, T, Vilisics, F. (2007) Changes of isopod assemblages along 488 an urban-suburban-rural gradient in Hungary. European Journal of Soil Biology, 43:158-165.

489 Jaccard, P. (1901) Distribution de la flore alpine dans le bassin des Dranses et dans quelques 490 régions voisines. Bulletin de la Société Vaudoise des Sciences Naturelles, 37: 241-272.

491 Jost, L (2006) Entropy and diversity. Oikos 113, 363-375.

492 Kavazos, CRJ, Wallman, JF. (2012) Community composition of carrion-breeding 493 blowflies (Diptera: Calliphoridae) along an urban gradient in south-eastern Australia. Landscape 494 and Urban Planning, 106; 183-190.

495 Klein, BC. (1989) Effects of forest fragmentation on dung and carrion beetle communities in 496 central Amazonia. Ecology. 70; 1715-1725.

497 Kotze, J, Venn, S, Niemelä, J, Spence, J. (2011) Effects of Urbanization on the Ecology and 498 Evolution of Arthropods. Urban Ecological Patterns, Processes, \& Applications, 159-166. 
499 La Sorte, FA, Aronson, MFJ, Williams, NSG, Celesti-Grapow, L, Cilliers, S. (2014) Beta

500 diversity of urban floras among European and non-European cities. Global Ecology and

501 Biogeography, 23, 769-779.

502 Lessard, JP, Buddle, CM. (2005) The effects of urbanization on ant assemblages (Hymenoptera: 503 Formicidae) associated with the Molson Nature Reserve, Quebec. The Canadian Entomologist, 504 137; 215-225.

505 Magura, T, Lovei, G. L. \& Tothmeresz, B. (2010) Does urbanization decrease diversity in 506 ground beetle (Carabidae) assemblages? Global Ecology Biogeography, 19; 16-26.

507 Magura, T, Nagy, D, Tothmeresz, B. (2013) Rove beetles respond heterogeneously to 508 urbanization. Journal of Insect Conservation. 17; 715-724.

509 Magura, T, Tothmeresz, B, Hornung, E, Horvath, R. (2008) Urbanization and Ground-dwelling 510 invertebrates. Urbanization: $21^{\text {st }}$ Century Issues and Challenges. Luca N. Wagner, Nova Science 511 Publishers, Inc. 213-225.

512 Magura, T, Tóthmérész, B. \& Lövei, GL. (2006) Body size inequality of carabids along an 513 urbanisation gradient. Basic \& Applied Ecology. 7, 472-482 (2006).

514 Martinson, HM, Raupp, MJ. (2013) A meta-analysis of the effects of urbanization on ground 515 beetle communities. Ecosphere, 4(5);1-24

516 McDonnell, MJ, Hahs, AK. (2008) The use of gradient analysis studies in advancing our 517 understanding of the ecology of urbanizing landscapes: Current status and future directions.

518 Landscape Ecology, 23; 1143-1155.

519 McKinney, ML. (2008) Effects of urbanization on species richness: A review of plants and 520 animals. Urban Ecosystems, 11:161-176.

521 Munshi-South J, Zolnik CP, Harris SE (2016) Population genomics of the Anthropocene: 522 urbanization reduces the evolutionary potential of small mammal populations. Evolutionary 523 Applications.

524 Niemelä, J, Kotze, DJ, Venn, S, Penev, L, Stoyanov, I, Spence, JD, Hartley, D, de Oca, EM. 525 (2002) Carabid beetle assemblages (Coleoptera: Carabidae) across urban-rural gradients: and 526 international comparison. Landscape Ecology. 17; 387-401.

527 Niemelä, J, Kotze, DJ. (2009) Carabid beetle assemblages along urban to rural gradients: A 528 review. Landscape \& Urban Planning, 92; 65-71.

529 NYC Department of City Planning-Land Use Facts. New York City Department of City Planning, 53027 May 2002.

531 Oksanen, J, Blanchet, FG, Kindt, R, Legendre, P, Minchin, PR, O'Hara, RB, Simpson, GL, 532 Solymos, P, Stevens, MHH and Wagner, H. (2016). vegan: Community Ecology Package. R 533 package version 2.3-4. https://CRAN.R-project.org/package=vegan 
534 Ordeñana, M, Crooks, KR, Boydston, EE, Fisher, RN, Lyren, LM, Siudyla, S, Haas, OD, Harris

535 S, Hathaway, SA, Turschak, GM, Miles, AK, Van Vuren, DH. 2010. Effects of urbanization on

536 carnivore species distribution and richness. Journal of Mammalogy. 91, 1322-1331 (2010).

537 Pauleit, S \& Breuste, JH. 2011. Land Use and Surface Cover as Urban Ecological Indicators.

538 Urban Ecology: Patterns, Processes and Applications, Oxford University Press, pp. 19 - 30.

539 Peck, SB. (1981) Distribution and biology of flightless carrion beetle Necrophilus pettiti in

540 eastern North America (Coleoptera; Silphidae). Entomological News 92(5):181-185.

541 Pickett, STA, Cadenasso, ML, Grove, JM, Boone, CG, Groffman, PM, Irwin, E, Kaushal, SS, 542 Marshall, V, McGrath, BP, Nilon, CH, Pouyat, RV, Szlavecz, K, Troy, A, Warren, P. (2011)

543 Urban ecological systems: Scientific foundations and a decade of progress. Journal of

544 Environmental Management, 92; 331-362.

545 Pirone, DJ \& Sullivan, DJ. (1980) Ecology of necrophilous and carpophilous Coleoptera in a

546 southern New York woodland (phenology, aspection, trophic and habitat preferences). New York

547 Entomological Society LXXXVIII(3), pp 186-196.

548 Pouyat, RV, Yesilonis, ID, Russell-Anelli, J, Neerchal, NK. (2007) Soil chemical and physical 549 properties that differentiate urban land-use and cover types. Soil Science Society of America 550 Journal, 71(3), 1010-1019.

551 Ratcliffe, BC. (1996) The carrion beetles (Coleoptera: Silphidae) of Nebraska. Bulletin of the 552 University of Nebraska State Museum, 13; 1-100.

553 R Development Core Team (2008). R: A language and environment for statistical computing. R

554 Foundation for Statistical Computing, Vienna, Austria. ISBN 3-900051-07-0, URL http://www.R-

555 project.org.

556 Sattler, T, Duelli, P, Obrist, MK, Arlettaz, R \& Moretti, M. (2010) Response of arthropod

557 species richness and functional groups to urban habitat structure and management. Landscape

558 Ecology, 25, 941-954.

559 Saunders, DA, Hobbs, RJ \& Margules, CR. (1991) Biological consequences of ecosystem

560 fragmentation: a review. Conservation Biology, 5, 18-32.

561 Savage, AM, Hackett, B, Guénard, B, Youngsteadt, EK, Dunn, RR. (2015) Fine-scale

562 heterogeneity across Manhattan's urban habitat mosaic is associated with variation in ant

563 composition and richness. Insect Conservation and Diversity. 8; 216-228.

564 Scott MP, Traniello JFA. (1990.) Behavioral and ecological correlates of male and female

565 parental and reproductive success in the burying beetle, Nicrophorus orbicollis. Animal Behavior.

566 39: 274-83.

567 Scott, MP. (1998) The ecology and behavior of burying beetles. Annual Reviews of Entomology,

568 43:595-618. 
569 Scott, MP, Traniello, JFA, Fetherston, IA. (1987) Competition for Prey Between Ants and 570 Burying Beetles (Nicrophorus Spp): Differences Between Northern and Southern Temperate 571 Sites. Psyche A Journal of Entomology, 94, 325-332 (1987).

572 Seewagen, CL, Slayton, EJ (2008) Mass Changes of Migratory Landbirds During Stopovers in a 573 New York City Park. The Wilson Journal of Ornithology, 120(2): 296-303.

574 Simpson, EH. (1949). Measurement of diversity. Nature, 163: 688.

575 Stott, I, Soga, M, Inger, R, Gaston, KJ. (2015) Land sparing is crucial for urban ecosystem 576 services. Frontiers in Ecology and the Environment, 13; 387-393.

577 Sugiura, S, Tanaka, R, Taki, H, Kanzaki, N. (2013). Differential responses of scavenging 578 arthropods and vertebrates to forest loss maintain ecosystem function in a heterogeneous 579 landscape. Biological Conservation, 159; 206-213.

580 Trumbo, ST. (1990). Reproductive Success, Phenology and Biogeography of Burying Beetles 581 (Silphidae, Nicrophorus) The American Midland Naturalist; The University of Notre Dame. 124, 582 1-11.

583 Trumbo, ST, Bloch, PL. (2000). Habitat fragmentation and burying beetle abundance. Journal of 584 Insect Conservation, 4: 245-252.

585 Ulrich, W, Komosiński, K, Zalewski, M. (2008). Body size and biomass distributions of carrion 586 visiting beetles: do cities host smaller species? Ecological Resources. 23, 241-248.

587 United Nations, Department of Economic and Social Affairs, Population Division (2014). World 588 Urbanization Prospects: The 2014 Revision, Highlights (ST/ESA/SER.A/352).

589 United States Census Bureau (2010) "Decennial Census 2010" Census, U.S. Department of 590 Commerce. Web. February 29, 2016. http://www.census.gov/quickfacts/table/PST045215/36119

591 Varet, M, Pétillon, J \& Burel, F. (2011) Comparative responses of spider and carabid beetle 592 assemblages along an urban-rural boundary gradient. Journal of Arachnology, 39; 236-243

593 Watts, C, Lariviere, M. (2004) The importance of urban reserves for conserving beetle 594 communities: a case study from New Zealand. Journal of Insect Conservation, 47-58.

595 Wolf, JM, Gibbs, JP. (2004) Silphids in urban forests: Diversity and function. Urban Ecosystems, 596 7:371-384.

597 Wright, DH, Reeves, JH. (1992). International Association for Ecology On the Meaning and 598 Measurement of Nestedness of Species Assemblages. Oecologia 92, 416-428.

599 Xian, G, Homer, C, Demitz, J, Fry, J, Hossain, N, Wickham, J. (2011) Change of impervious 600 surface area between 2001 and 2006 in the conterminous United States. Photogrammetric 
601 Engineering and Remote Sensing, 77:758-762. 


\section{Tables \& Figures}

603 Table 1. Characteristics, classification and quantification of urbanization at each sample sites, 604 along with species richness, and species diversity measures at each site (urban=orange, 605 suburban=teal, rural=purple).

\begin{tabular}{llcccc}
\hline $\begin{array}{c}\text { Site } \\
\text { Code }\end{array}$ & \multicolumn{1}{c}{ Site Name } & $\begin{array}{c}\text { Site } \\
\text { Classification }\end{array}$ & $\begin{array}{c}\text { Mean \% } \\
\text { Impervious } \\
\text { Surface }\end{array}$ & $\begin{array}{c}\text { Species } \\
\text { Richness } \\
\text { (species } \\
\text { number) }\end{array}$ & $\begin{array}{c}\text { Species } \\
\text { Diversity } \\
\text { (Simpson's } \\
\text { 1/D) }\end{array}$ \\
\hline NYBG & New York Botanical Garden & Urban & $60.88 \%$ & 2 & 1.61 \\
HBP & High Bridge Park & Urban & $60.54 \%$ & 6 & 1.84 \\
CP & Central Park & Urban & $60.24 \%$ & 6 & 2.66 \\
IHP & Inwood Hill Park & Urban & $29.97 \%$ & 6 & 2.94 \\
VCP & Van Cortlandt Park & Urban & $27.97 \%$ & 5 & 2.34 \\
SWP & Saxon Woods Park & Suburban & $17.63 \%$ & 5 & 2.37 \\
LCC & Louis Calder Center & Suburban & $10.57 \%$ & - & - \\
LCC1 & Louis Calder Center Sample 1 & - & - & 3 & 3.20 \\
LCC2 & Louis Calder Center Sample 2 & - & - & 4 & 2.59 \\
LCC3 & Louis Calder Center Sample 3 & - & - & 5 & 2.87 \\
CSH & Convent of Sacred Heart & Suburban & $11.14 \%$ & 4 & 2.31 \\
RSP & Rockefeller State Park & Suburban & $4.74 \%$ & 5 & 1.75 \\
MRG & Mianus River Gorge Preserve & Suburban & $0.64 \%$ & 6 & 2.59 \\
CT & Western Connecticut & Rural & $0.89 \%$ & 3 & 2.38 \\
CAT & Catskills & Rural & $0.46 \%$ & 5 & 1.68 \\
CFP & Clarence Fahnestock State Park & Rural & $0.20 \%$ & 4 & 1.77 \\
\hline
\end{tabular}


606 Table 2. Abundance data for eight carrion beetle (Family: Silphidae) species at all site locations 607 (site abbreviations and classification found in Table 1).

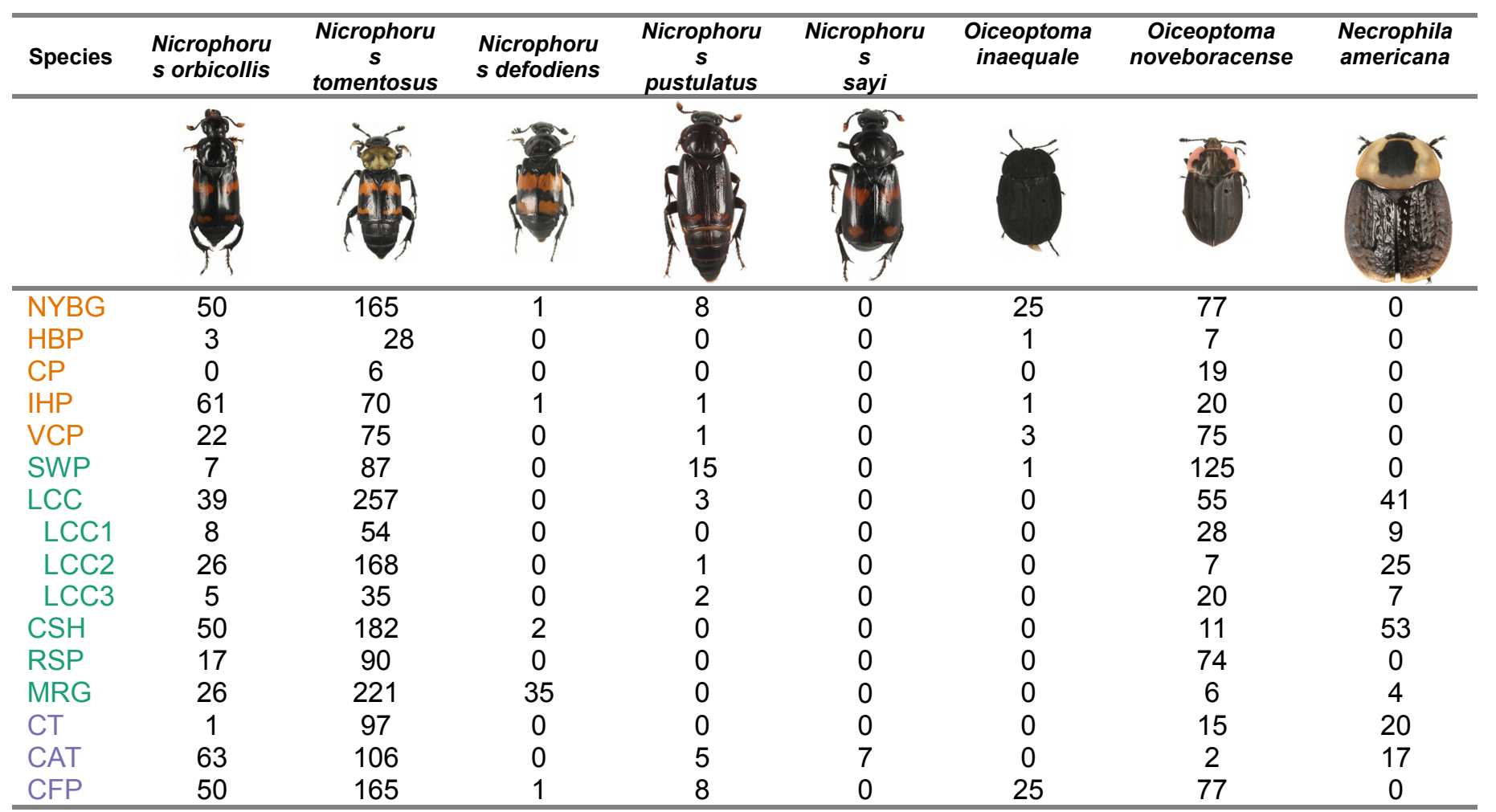


608 Table 3. Pairwise Jaccard community similarity index values calculated between all sample sites 609 (site abbreviations and classification located in Table 1).

\begin{tabular}{|c|c|c|c|c|c|c|c|c|c|c|c|c|c|}
\hline & NYBG & $\mathrm{HBP}$ & $\mathrm{CP}$ & $\mathrm{IHP}$ & $\mathrm{VCP}$ & SWP & LCC & $\mathrm{CSH}$ & $\mathrm{RSP}$ & MRG & CT & CAT & CFP \\
\hline NYBG & - & 0.667 & 0.333 & 1.000 & 0.833 & 0.833 & 0.571 & 0.571 & 0.571 & 0.500 & 0.571 & 0.625 & 0.500 \\
\hline HBP & & - & 0.500 & 0.667 & 0.800 & 0.800 & 0.500 & 0.500 & 0.500 & 0.750 & 0.500 & 0.750 & 0.429 \\
\hline CP & & & - & 0.333 & 0.400 & 0.400 & 0.400 & 0.400 & 0.400 & 0.667 & 0.400 & 0.500 & 0.333 \\
\hline IHP & & & & - & 0.833 & 0.833 & 0.571 & 0.571 & 0.571 & 0.500 & 0.571 & 0.750 & 0.500 \\
\hline VCP & & & & & - & 1.000 & 0.667 & 0.667 & 0.429 & 0.600 & 0.429 & 0.875 & 0.571 \\
\hline SWP & & & & & & 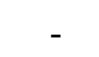 & 0.667 & 0.667 & 0.429 & 0.600 & 0.429 & 0.875 & 0.571 \\
\hline LCC & & & & & & & - & 1.000 & 0.667 & 0.600 & 0.667 & 0.875 & 0.833 \\
\hline $\mathrm{CSH}$ & & & & & & & & - & 0.667 & 0.600 & 0.667 & 0.571 & 0.833 \\
\hline RSP & & & & & & & & & - & 0.600 & 1.000 & 0.625 & 0.833 \\
\hline MRG & & & & & & & & & & $\begin{array}{ll}- & \text { - }\end{array}$ & 0.600 & 0.875 & 0.500 \\
\hline CT & & & & & & & & & & & - & 0.875 & 0.600 \\
\hline CAT & & & & & & & & & & & & - & 0.875 \\
\hline CFP & & & & & & & & & & & & & - \\
\hline
\end{tabular}


610 Figure 1. Geographic location of study sites surrounded by $2 \mathrm{~km}$ buffer circles. Urban (orange), 611 suburban (teal), and rural (purple) sites were classified according to impervious surface in these 612 buffers as described in the text. Green areas represent no impervious surface, whereas areas of 613 increasing pink coloration denote increasing percent impervious surface as reported in the 2011 614 National Landcover Database (Xian, et al. 2011). Site abbreviations follow Table 1.

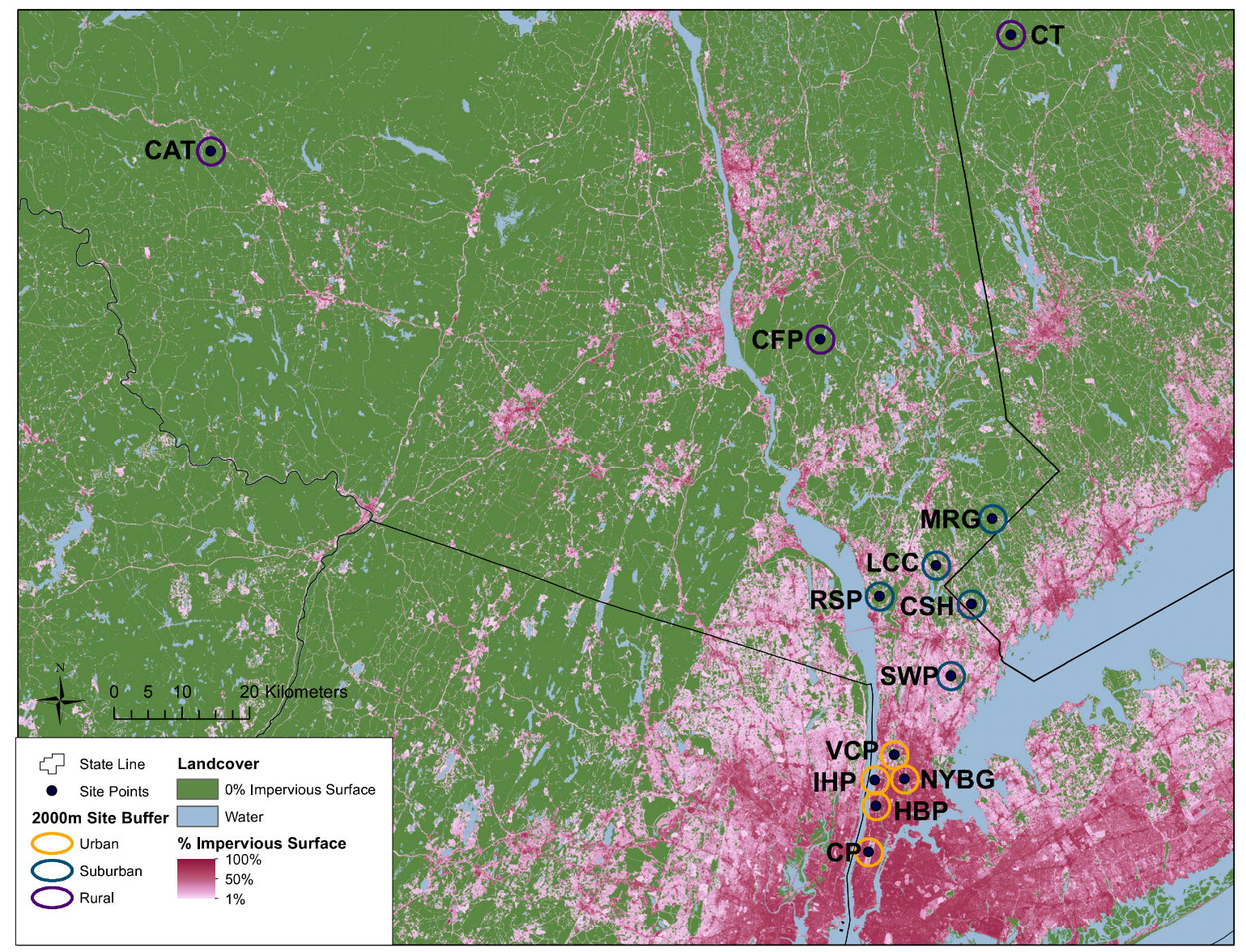


615 Figure 2. Relative abundance (\%) of species across site classes; urban (orange), suburban (teal), 616 rural (purple) sites. Bold lines within the boxes indicate the median value, the colored boxes 617 represent the inter-quartile range (Quartile 1- Quartile 3), the whiskers extend 1.5* IQR, and the 618 dots represent outlier values.

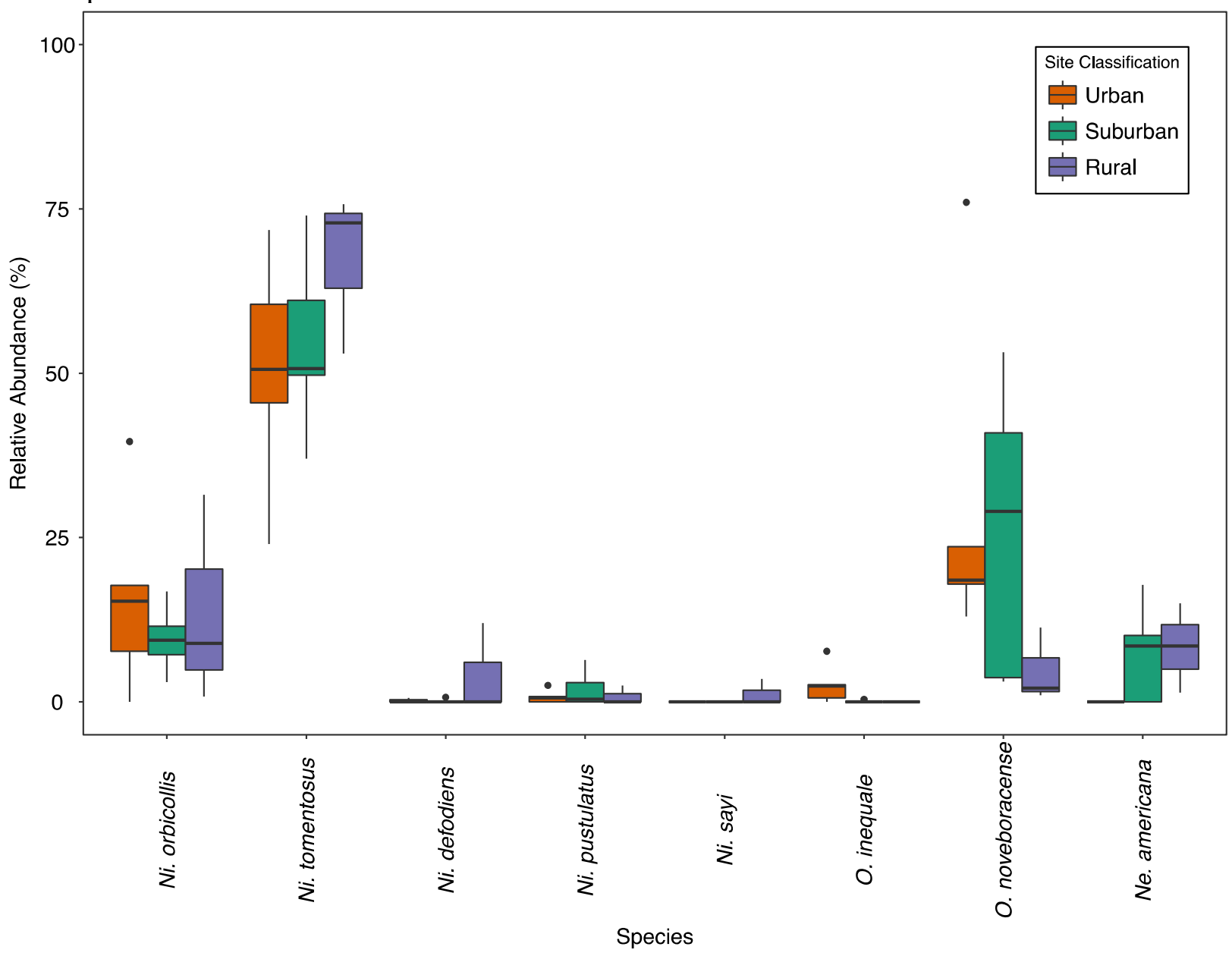


619 Figure 3. Relative abundance (\%) of species across three sampling surveys (Late June, Mid July, 620 Late July) at the Louis Calder Center site in Armonk, NY.

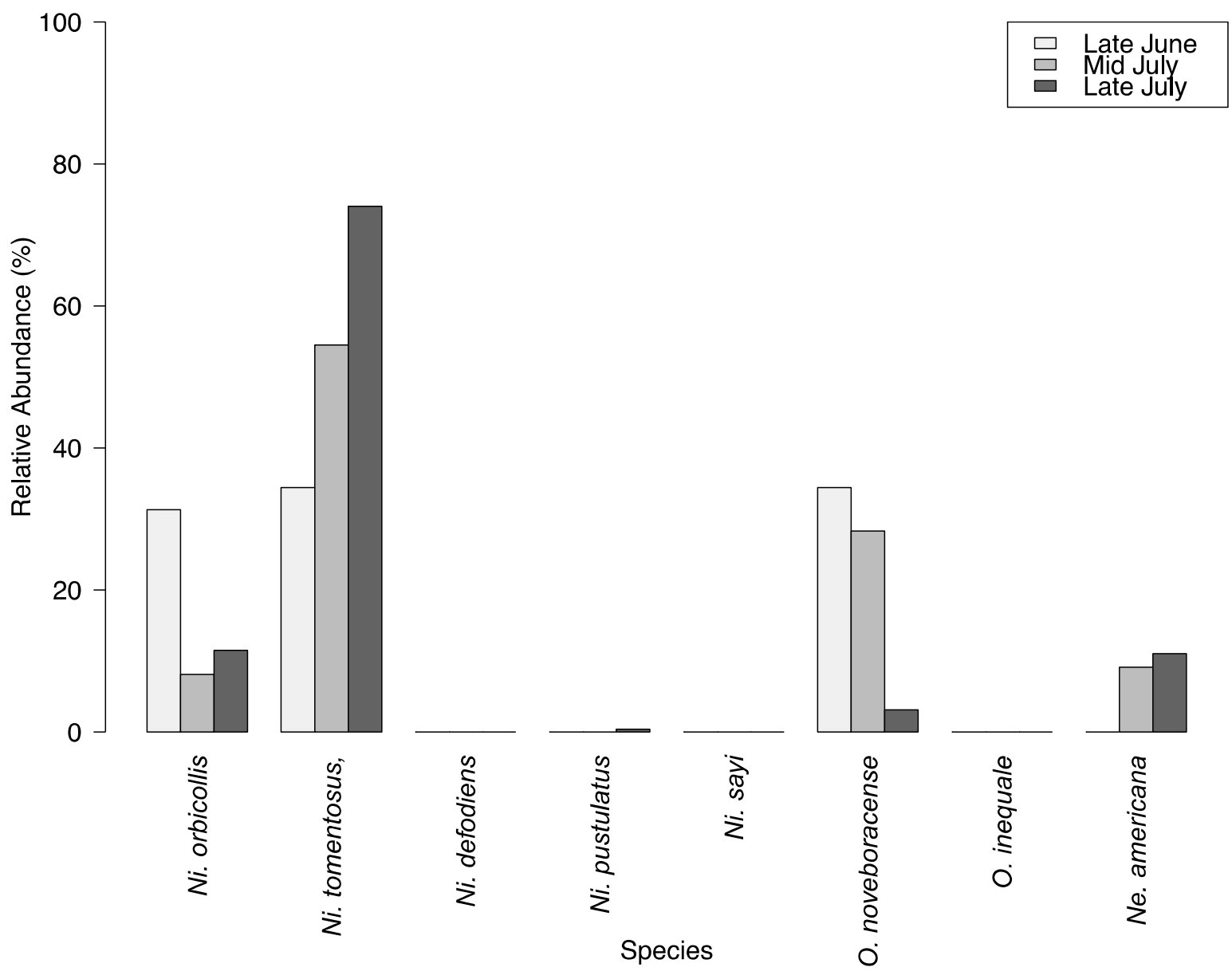


621 Figure 4. Relative abundance of species at the Louis Calder Center site in 1974 (Pirone and 622 Sullivan, 1980) and in 2015.

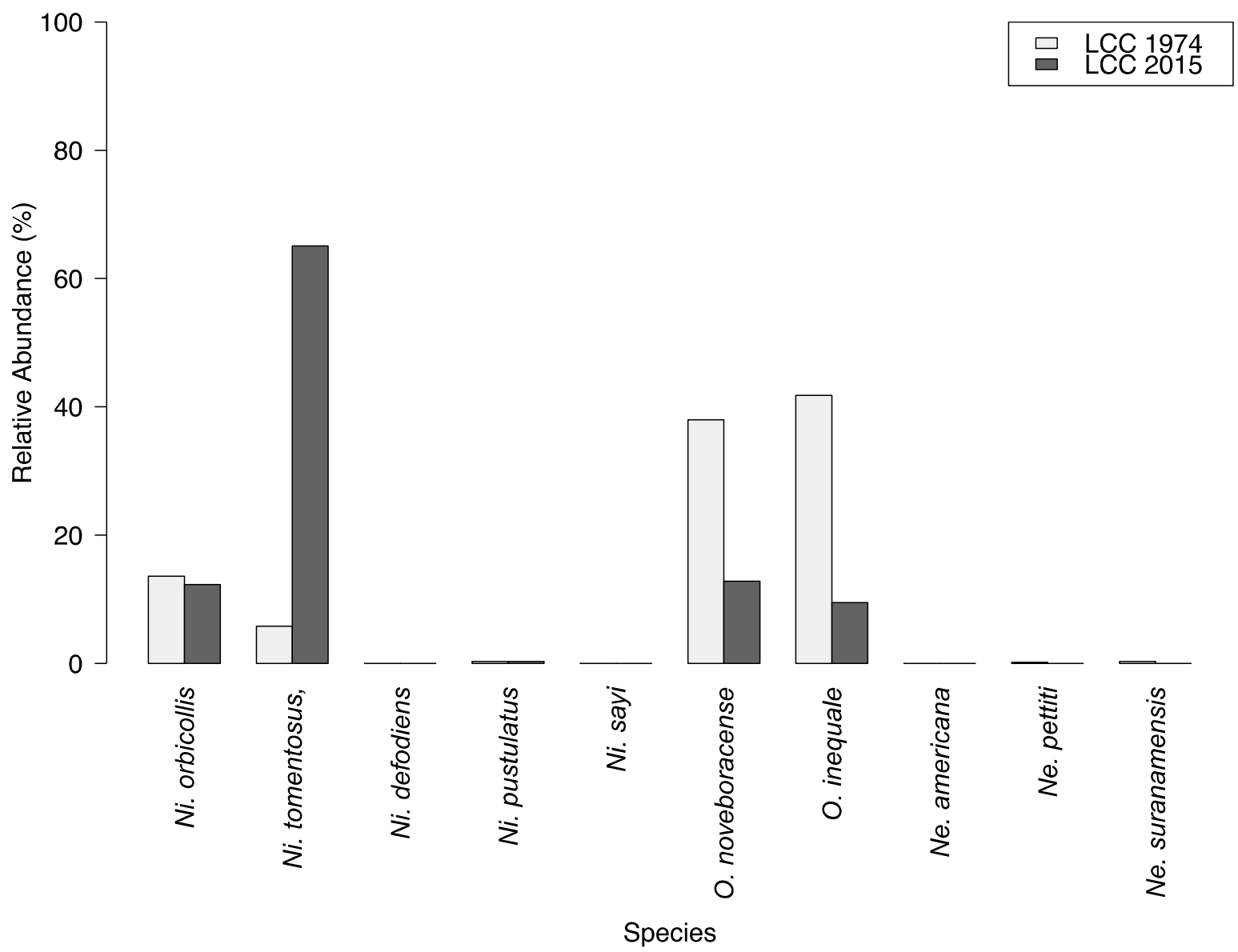


623 Figure 5. Non-metric multidimensional scaling (NMDS) of abundance of carrion beetle species 624 at each site grouped by site class as a convex hull.

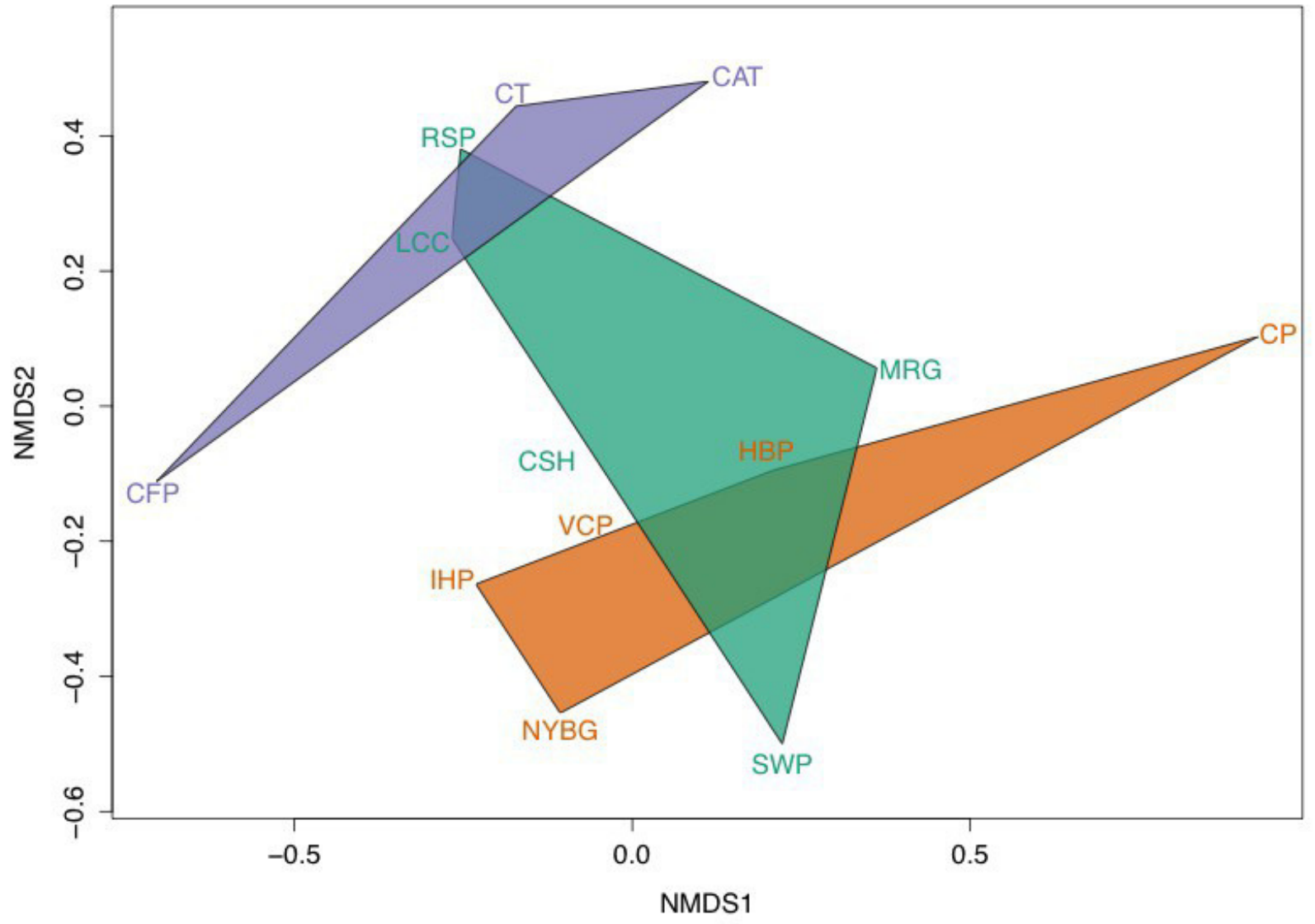

625 Figure 6. Hierarchical cluster analysis of sites(abbreviations found in Table 1) based on (A) the 626 nestedness component of the Jaccard Similarity Index for beta diversity (ßjne) and (B) the 
627 turnover component (ßjtu).

(A)

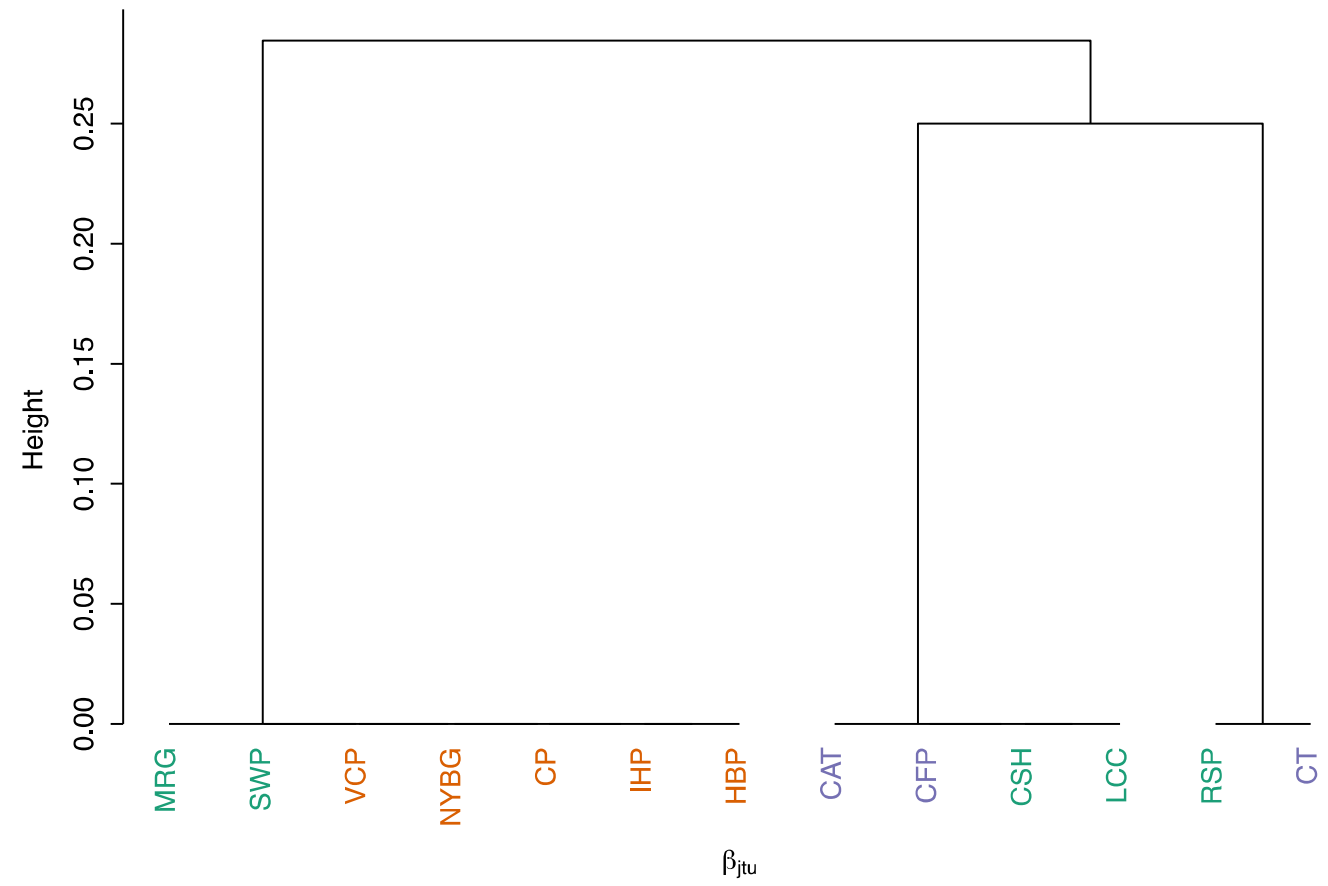

(B)

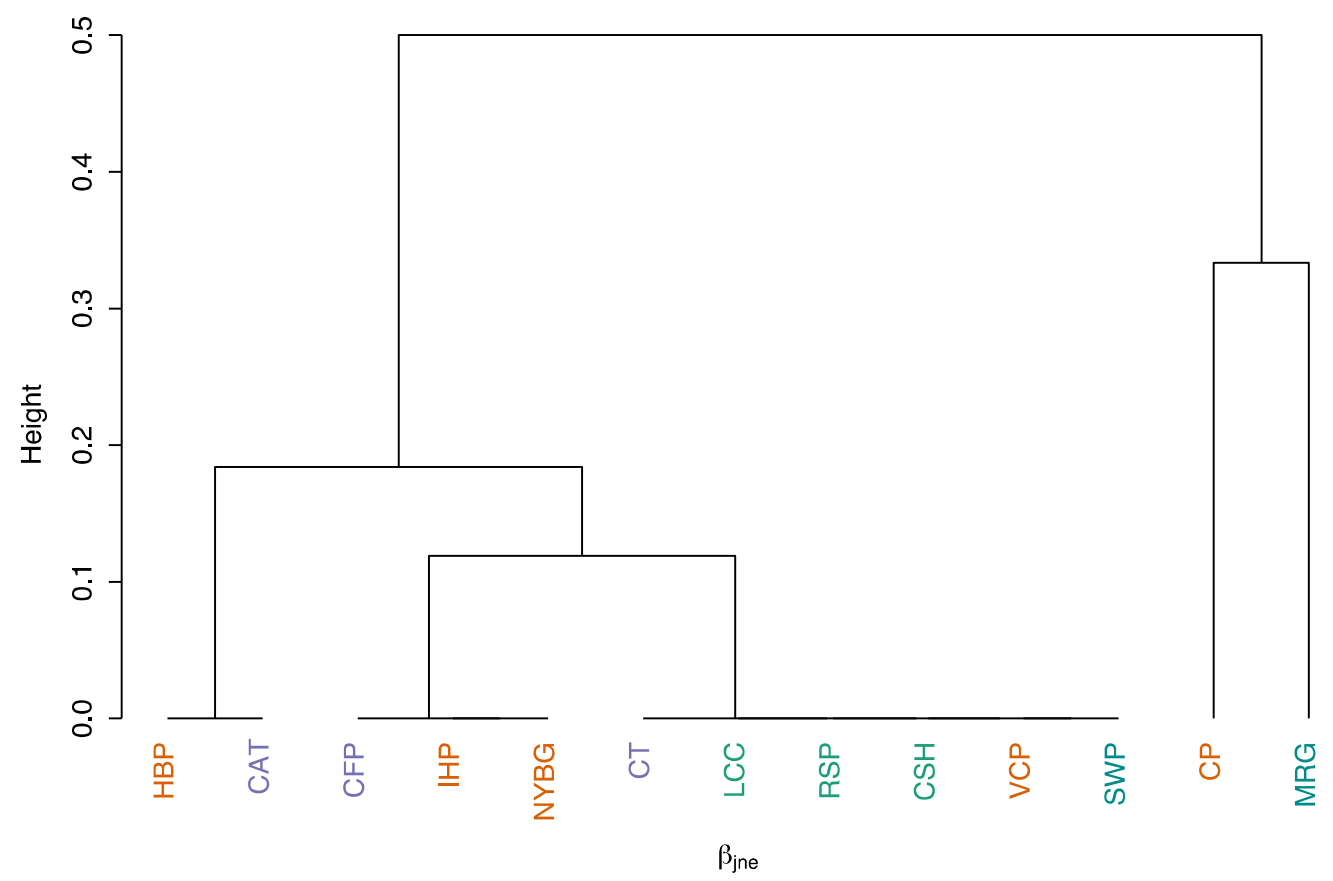

